\title{
High Temperature Performance of a prefabricated concrete sandwich panel
}

\author{
Shouqian $\mathrm{Liu}^{1 *}$, Zhan Song ${ }^{1}$ \\ ${ }^{1}$ Shandong Jianda Education Real Estate Co.Ltd, 1000 Fengming Road Licheng District Jinan Shan Dong, China
}

\begin{abstract}
The innovative sandwich wall panel studied in this paper can be used as the load-bearing member of the structure. In addition to the traditional sandwich panel structure, the new panel system also has the characteristics of spiral stirrups along the section of the core column, $650 \mathrm{~mm}$ column spacing, foam concrete for insulation layer and self-compacting concrete for outer layer. In addition, in order to improve the overall strength and stiffness of the panel, a unique wire system consisting of two vertical wire mesh connected by a short horizontal steel bar is adopted in the concrete layer. In order to study the mechanical properties of the new panel system at high temperature, ABAQUS simulation was carried out. The simulation results show that the new precast concrete sandwich wall system has good resistance to high temperature and still has good bearing capacity after high temperature.
\end{abstract}

\section{Introduction}

Fires cause huge losses every year. In particular, it is very important to limit the fire spread in a variety of ways, especially in the design of public buildings[1-2], compared with the multiple causes of fire spread. Sandwich plate is an important substitute to solve the problem of high temperature resistance of concrete. Several authors have studied the performance of panels capable of presenting a central insulating material. Sani Mohammed[3] studied four samples, including a control sample. Based on the results obtained and subsequent analysis, it is observed that the heat transfer through the sample is proportional to the length of the thermal path.Jacob M.[4] studies the thermal conductivity of graphite foam core sandwich panels. Thermal measurements of sandwich panels indicate that if the adhesive used for bonding panels also has high thermal conductivity, the foam core may provide very high thermal conductivity according to the thickness of the foam. The deformation of sandwich plates caused by asymmetric heat load is measured. It is proved that graphite core can reduce the deformation caused by thermal gradient of sandwich plates exposed for a long
time.In the study of Amnoiy Reengwareel [5], Chinese plywood, rubber plywood and teak plywood were used. The results of finite element simulation show that the domestic plywood reinforced sandwich wall has the best heat reduction performance.Liang Xiangwei[6] found that the mixture containing steel slag and hybrid fiber has excellent fire resistance. The results show that fiber reinforced concrete as the core material of sandwich plate can significantly resist high temperature. In this study, a novel concrete sandwich panel structure system is proposed. Compared with ordinary sandwich panels, the sandwich panel has the following typical characteristics: the steel bar core is restrained by spiral stirrups along the cross section of the panel, the spacing between columns is $650 \mathrm{~mm}$, and the foam concrete is used as insulation layer between the outer layers, and self compacting concrete is applied to the high fluidity structure layer. In order to meet the strength and stiffness requirements in the application of multi-storey and high-rise buildings, a threedimensional steel wire mesh system composed of vertical steel wire mesh connected by two horizontal steel bars is used in each layer of concrete. As shown in Figure 1. 


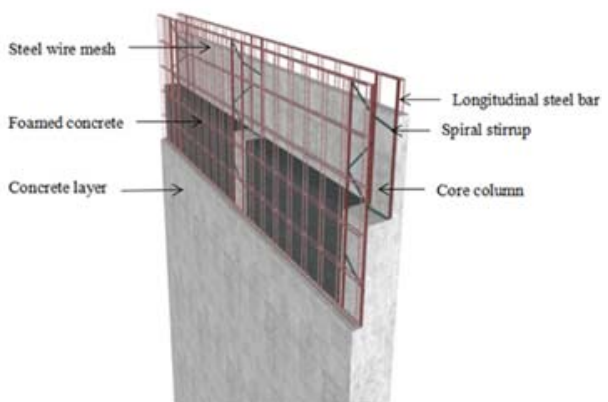

Fig. 1. Prefabricated sandwich panel

\section{Specimen Information}

ABAQUS simulates two $1200 \mathrm{~mm}$ high wall specimens. The length and width of the specimens are shown in Fig. 2 and Fig. 3. The planar mesh is consisted of steel wire in two orthogonal directions with same spacing $50 \mathrm{~mm}$ and the diameter of steel wire is $3 \mathrm{~mm}$.. Two the foam concrete

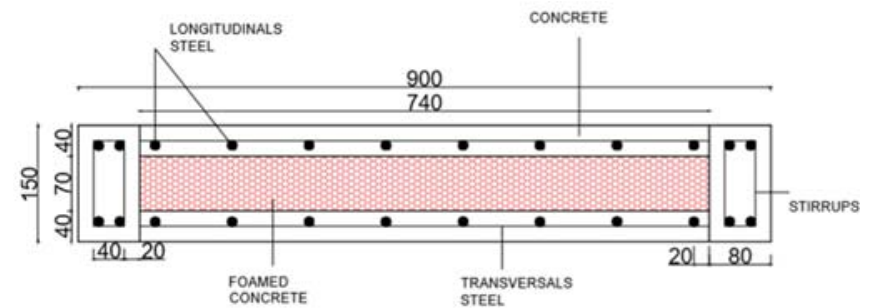

Fig. 2. Cross-section of SWP1

The concrete part model and the reinforced skeleton model are shown in Fig.4. In the damage plasticity constitutive of concrete, three sets of data need to be input. The first group mainly defines the yield criterion, flow rule and strengthening criterion of concrete, Including: Expansion angle (which has a great influence on the torsion of concrete, this article uses the recommended value of $30^{\circ}$ by ABAQUS; Eccentricity of flow potential (taken as 0.1), the ratio of yield stress in isoaxial compression to yield stress in uniaxial compression (taken as 1.16), The ratio of the second stress invariant on the tension meridian to the pressure meridian (take 0.6667), Viscosity parameters (have a great impact on model convergence, this article takes 0.005 to obtain convergence); The second group is the concrete

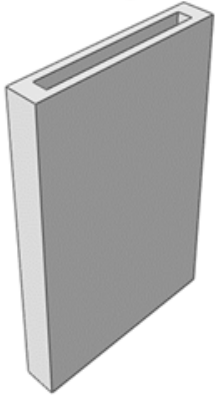

(a)Concrete interlayer is $70 \mathrm{~mm}$ and $100 \mathrm{~mm}$ respectively. After 28 days of curing, the actual compressive strength is $45.6 \mathrm{Mpa}$. The yield strength and ultimate tensile strength of steel wire are $550 \mathrm{MPa}$ and $670 \mathrm{mpa}$ respectively, and the yield strength of steel bar is $570 \mathrm{Mpa}$.

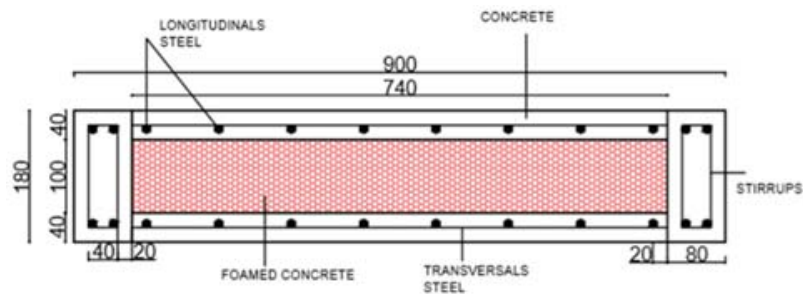

Fig. 3. Cross-section of SWP2

compression data and compression damage factors. This simulation does not consider the recovery of tensile stiffness, that is, $\mathrm{Wt}=0$; the third group is the concrete tensile data and tensile damage factor. This simulation assumes that the compression stiffness recovery ratio is 1 , that is, $\mathrm{Wc}=1$.The sandwich panel walls were exposed to fire for a period of 3 hours. The standard ISO-834 fire curve was applied to the exposed surface as a thermal load, through the convection and radiation heat transfer mechanisms. Only one face of the wall was exposed to fire over its entire surface (main face or main surface). A constant coefficient of convection $15 \mathrm{w} / \mathrm{m}^{2} \mathrm{k}$ was used for the exposed surface, since heat radiation was taken into account separately. An emissivity value of 0.5 related to the radiative heat flux was used for the walls.

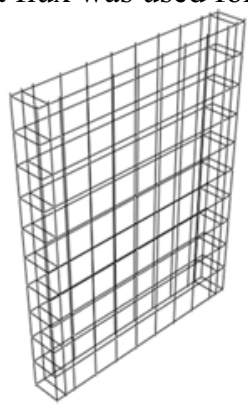

(b) Steel part

Fig. 4. Finite element model of slab and wall components 


\section{Results analysis}

The results from the described heat transfer analysis were applied as a thermal load to the mechanical model. In order to compare these results, the loading method is the same as the static load analyses. Therefore, the finite element meshes and the node numbering were exactly the same as those used in the thermal analysis model. But boundary conditions which were not considered in the
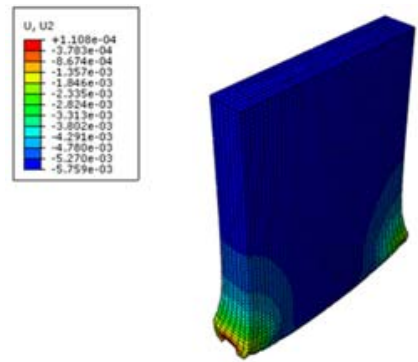

(a) Wall thermal-mechanic thermal analysis were added precisely Displacement/rotation and the interactions were removed.

\subsection{Calculation results of sample SPW1}

The thermal calculation results of sample SWP1 are shown in Figure 5.
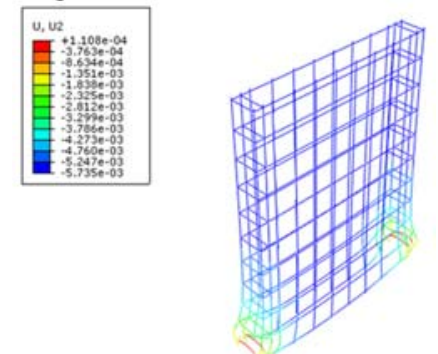

(b) Reinforced mesh thermal-mechanic cloud

Fig. 5. Calculation results of SPW1

Figure 6 shows the wall deformation curve after exposure to high temperature and the deformation curve at ambient temperature. From 0 to $175 \mathrm{kN}$ and 0 to $125 \mathrm{kN}$, the deformation curves of the two graphs are straight lines. The applied load value is proportional to the model. The model is in linear phase, which corresponds to the definition of linear phase in material mechanics. With the increase of stress, cracks appear. When the load increases to $150 \mathrm{kn}$, the sample is no longer in linear phase after fire, and the applied load value is no longer proportional to the

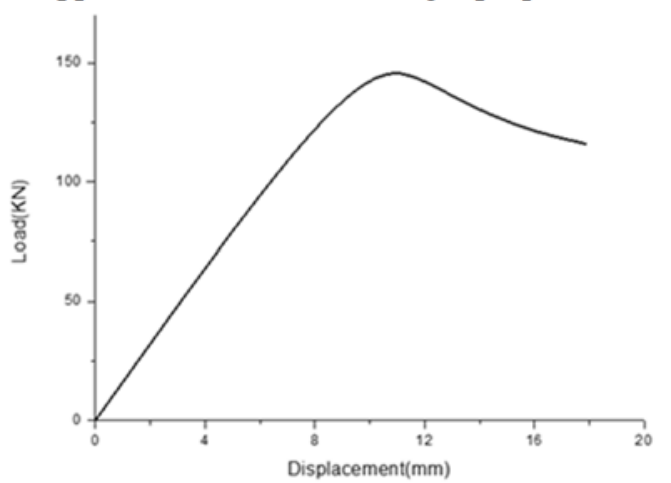

(a) SPW1 after fire displacement value generated by the sample. While the load is maintained, the displacement of the sample will continue to increase. When the observed deformation at ambient temperature increases from $5 \mathrm{~mm}$ to $14 \mathrm{~mm}$, the sample is destroyed. The deformation observed in the center of the wall expands on both sides, especially at the bottom. The fire significantly weakened the panel and the bearing capacity of the wall decreased, resulting in the increase of deformation after fire.

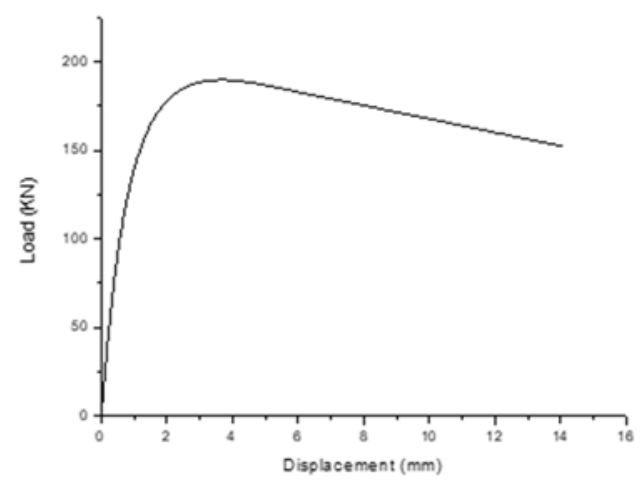

(b) SPW1 at ambient temperature

Fig.6. Calculation results of SPW1 Concrete load-displacement curve after fire and at ambient temperature

After the fire and at ambient temperature, it can be seen from the steel strain in Figure 7. After loading from 0 to $400 \mathrm{KN}$, the value of applied load is proportional to the value of panel deformation maintained in traction. It accords with the definition of linear stage in material mechanics. The increase of load does increase the deformation of reinforcement. When the load is $400 \mathrm{kN}$, the strain of steel bar has been greatly increased. The maximum strain after fire is $150 \mu \varepsilon$ and that before fire is $60 \mu \varepsilon$. The fire greatly weakened the reinforcement and the tensile strength of the reinforcement decreased. When the concrete works with the crack and increases the load, the steel begins to yield and the strain increases. The model is broken. 


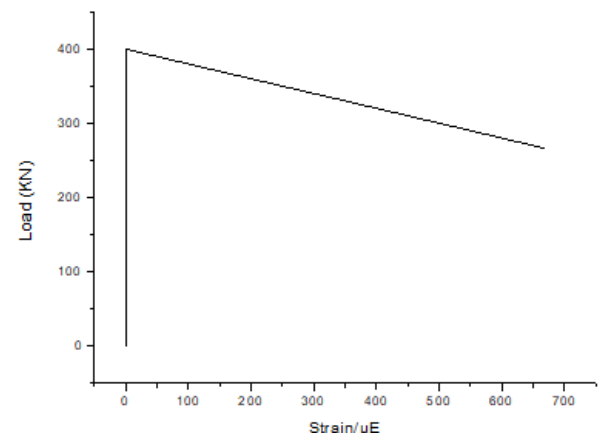

(a) After fire

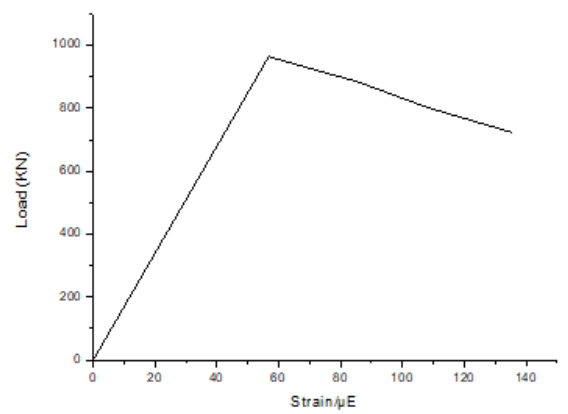

(b) At ambient temperature

Fig.7. Steel stress-strain curve after fire and at ambient temperature

\subsection{Calculation results of sample SPW2}

The thermal calculation results of sample SWP1 are shown in Figure 8.
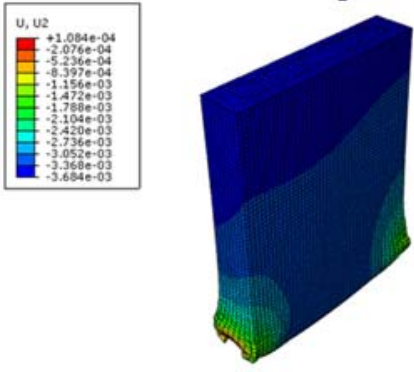

(a) Wall thermal-mechanic
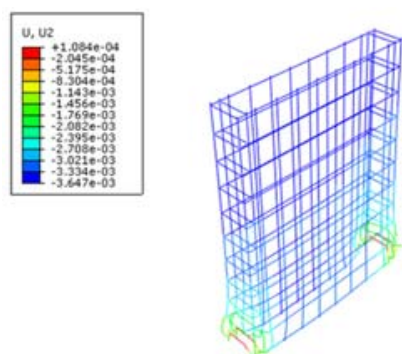

(b) Reinforced mesh thermal-mechanic cloud

Fig. 8. Calculation results of SPW2

The load increases to $280 \mathrm{kN}$, the sample after fire is no longer in the linear phase at this stage, the applied load value and the displacement value generated by the sample are no longer proportional. While maintaining the load, the displacement value of the sample will continue to increase. The sample was destroyed after the deformation increased from $4 \mathrm{~mm}$ to $16 \mathrm{~mm}$, which was greater than the

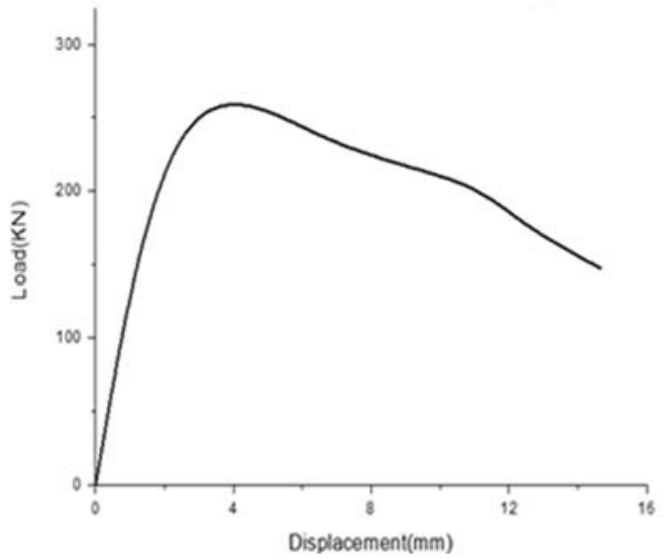

(a) SPW2 after fire deformation observed at ambient temperature which was from $3 \mathrm{~mm}$ to $9 \mathrm{~mm}$. The deformations observed in the center of the wall are widened on the sides and especially at the bottom. Fire considerably weakened the panel, the bearing capacity of the wall was reduced which caused the increase in deformation observed after fire.

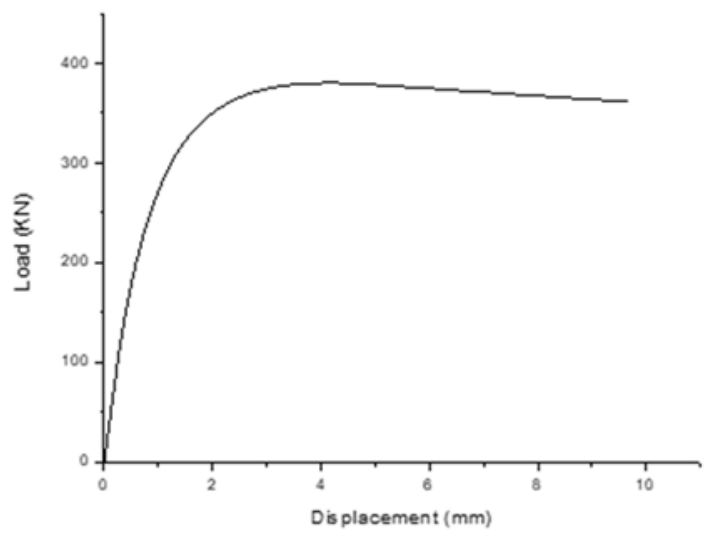

(b) SPW2 at ambient temperature

Fig.9. Calculation results of SPW1 Concrete load-displacement curve after fire and at ambient temperature

The load is from 0 to $820 \mathrm{KN}$ after, the value of the applied load is proportional to the value of the deformation of the panel which is in a state of traction. It meets the definition of linear stage in mechanics of materials. The increase in the load does make the deformation of the steel bar sufficiently large. With a load of $820 \mathrm{KN}$, the strain of the steel bar has increased greatly 
and the strain is $100 \mu \mathrm{E}$ against $40 \mu \mathrm{E}$ at ambient temperature.

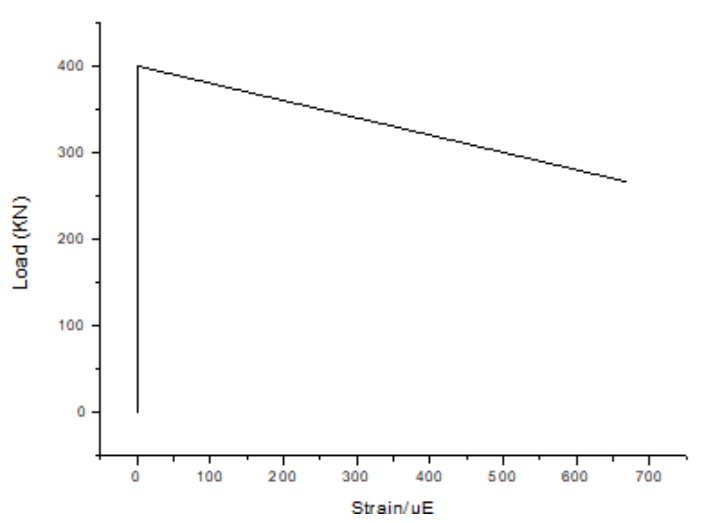

(a) After fire

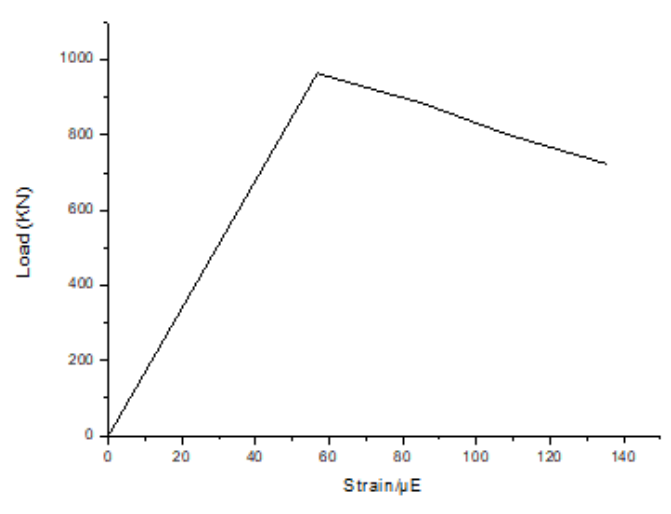

(b) At ambient temperature

Fig. 10. Steel stress-strain curve after fire and at ambient temperature

\section{Conclusions}

In this paper, the finite element software ABAQUS is used to analyze the thermodynamics of SPW1 and SPW2 sandwich panels. The results are helpful to improve our understanding of the thermomechanical properties of the new sandwich panels. The most significant results of thermo mechanical analysis are as follows: after fire, the bearing capacity of specimens decreases. The results show that the bearing capacity of SPW1 and SPW2 is greatly

\section{References}

1. A.M. Shakya, V.K.R. Kodur, Response of precast prestressed concrete hollowcore slabs under fire conditions, Engineering Structures 87 (2015) 126138.

2. Diogo Pereira, Antonio Gago, Jorge Proença, Tiago Morgado, Fire performance of sandwich wall assemblies, Composites Part B 93 (2016) 123-131.

3. Sani Mohammed Bida, Farah Nora Aznieta Abdul Aziz, Mohd Saleh Jaafar, Farzad Hejazi, Abu Bakar Nabilah, Thermal performance of super-insulated precast concrete structural sandwich panels, Energy \& Buildings 176 (2018) 418-430.

4. Jacob M. Quintana, Todd M. Mower, Thermomechanical behavior of sandwich panels with reduced after loading. After the fire, the deformation increases significantly, which is twice as much as that at the ambient temperature. In the new sandwich panel wall, the fire resistance of the wall is usually increased by increasing the thickness of the foam concrete in the middle layer, and the heat transfer through the wall is reduced, thus achieving a higher bearing capacity.

graphitic-foam cores, Materials and Design 135 (2017) 411-422.

5. Amnoiy Reengwaree1, Varunee Premanond, Sirichai Torsakul, A Study of Energy Saving in Building through Thermal Insulation with Plywood Inserted Honeycomb Sandwich Panels, Energy Procedia 34 (2013) $964-972$.

6. Xiangwei Liang, Chengqing $\mathrm{Wu}, \mathrm{Yu} \mathrm{Su}, \mathrm{Zhu}$ Chen, Zhongxian Li, Development of ultra-high performance concrete with high fire resistance, Construction and Building Materials 179 (2018) 400412. 